\title{
Prisión preventiva e ingreso a los centros penitenciarios. Una asignatura aún por resolver en México
}

\section{Pre-Trial Detention and Imprisonment: An Unresolved Issue in Mexico}

Ariadna Salazar Quiñonez ${ }^{1}$

CONACYT

México

\begin{abstract}
Resumen
El presente artículo tiene como objetivo conocer la efectividad de la reforma constitucional en materia de derechos humanos en México, cuyo eje central es la presunción de inocencia. La reforma es un mecanismo que permitiría el avance en la reducción de la población penitenciaria. Teniendo en consideración las anteriores modificaciones al modelo de justicia penal y la opción del país por el sistema acusatorio, la necesidad de apostar por el garantismo se convirtió en una decisión alentadora en un contexto nacional donde la vulneración de los derechos humanos y especialmente de los de las personas privadas de la libertad, sigue siendo un asunto aún por resolver. Así mismo, en el presente texto se aplicó la metodología del análisis de las cifras de personas privadas de la libertad de manera preventiva en los Estados de la República mexicana y en la Ciudad de México; el objetivo del análisis fue conocer, de manera certera, si se incrementó o no el número de personas en prisión como estaba previsto. Por lo tanto, se trae a discusión la necesaria consideración de la problemática de seguridad pública que se vive desde hace más de una década, la cual es un asunto que no termina de zanjarse y, aunque en algunas zonas se redujo, en otras se ha avivado. Es urgente que el Estado mexicano afronte la problemática carcelaria mediante salarios dignos, el tratamiento de las adicciones y la atención de la falta de
\end{abstract}

1Doctora con mención sobresaliente CUM LAUDE por la Universidad de Salamanca, España. Licenciada en Derecho por la Universidad Autónoma de Sinaloa, México y por la de Salamanca, España. Es Miembro del Sistema Nacional de Investigadores del CONACYT y de la Asociación de Constitucionalistas en España. Correo electrónico:ariadna_salazar@yahoo.com 
oportunidades, entre muchas otras cuestiones.

Palabras clave: prisión preventiva; derechos humanos; presunción de inocencia; garantismo; prisiones.

\begin{abstract}
This article aims to determine the effectiveness of the constitutional reform in the field of human rights in Mexico, whose central axis is the presumption of innocence. The reform is a mechanism that would enable the reduction of the prison population. Taking into consideration the previous modifications to the criminal justice model and the country's option for the accusatory system, the need to opt for support for due process guarantees became an encouraging decision in a national context where the violation of human rights, and especially those of persons deprived of liberty, continues to be an issue still to be resolved. Also, the present paper applied the methodology of analysis of the figures for persons in pre-trial detention in the states of the Mexican Republic and Mexico City; the objective of the study was to know, in an accurate manner, whether or not the number of persons in prison increased as expected. Therefore, the necessary consideration of the public security problem that has been going on for more than a decade is brought to the discussion, which is an issue that has not been resolved and, although in some areas it was reduced, in others it has been revived. It is urgent for the Mexican State to address the prison problem through decent wages, the treatment of addictions, and the attention to the lack of opportunities, among many other issues.
\end{abstract}

Keywords: pre-trial detention; human rights; presumption of innocence; support for due process guarantees; prisons.

\title{
Introducción
}

Con la reforma constitucional del 14 de julio de 2011, la presunción de inocencia se convertiría en eje central del proceso penal diseñado por el legislador; a la par fue reconocida ${ }^{2}$ la posibilidad de imponer prisión preventiva de manera oficiosa, es decir, sin previo análisis para determinados delitos. Aunado a ello, es necesario precisar que, el pasado mes de abril de 2019, se sufrió un importante revés en este sentido, debido a que se incrementó el número de delitos contenidos en el citado precepto.

2 Art. 19 de la Constitución Política de los Estados Unidos Mexicanos (en adelante CPEUM). 
Se advierte que, en lugar de avanzar en el reforzamiento institucional para eliminar dicho catálogo de delitos recogido previamente, dicho retroceso tiene un impacto directo en el respeto a la presunción de inocencia y en la espera de la decisión judicial sobre el proceso en su contra bajo privación de la libertad.

El presente trabajo busca conocer si acudir al modelo garantista trajo como resultado la reducción del número de personas recluidas en las entidades federativas o, si por el contrario, en la práctica sigue presente el modelo tradicional al momento de imponer la prisión preventiva.

Sin duda, el uso constante de la prisión preventiva sin justificación como medida cautelar trae consigo efectos perversos. Es evidente que la idea de dejar atrás los rasgos inquisitivos del anterior sistema no termina de consolidarse, está claro que el cuestionamiento angustioso que hacía el profesor Carranca y Rivas (1981) sobre "¿qué hacer con ellos?" no termina de tener una respuesta contundente por parte del Estado. En la actualidad, como respuesta se puede apreciar que, primero, se incluyeron ciertos delitos y, ahora, dicha lista se incrementó, en lugar de acudir al reforzamiento de los servicios cautelares para la imposición del abanico de medidas que se incluyeron como novedad.

\section{El diseño de la justicia penal en materia de derechos humanos}

El diseño del sistema de justicia penal estableció como eje central del proceso al derecho humano de la presunción de inocencia, junto con la dignidad humana. Si bien ya estaba reconocido que "toda persona se presume inocente y será tratada como tal en todas las etapas del procedimiento, mientras no se declare su responsabilidad mediante sentencia emitida por el Órgano jurisdiccional" (Art. 13 del CNPP), por mandato constitucional es uno de los derechos de la persona imputada.

En cuanto a la forma en que la persona imputada debe esperar el proceso, la autoridad judicial solo podrá autorizar como medidas cautelares, o providencias precautorias restrictivas de la libertad, las que estén establecidas en el Código Nacional de Procedimientos Penales y en las leyes especiales. Afortunadamente, el modelo de justicia penal estableció que la prisión preventiva, será de carácter excepcional y su aplicación se regirá en los términos previstos en tal Código (Artículo 19 del CNPP). Ahí es en donde se hace un giro en cuanto al modelo de justicia, más garantista para las personas que tienen un proceso abierto en su contra, pero hay que tener en consideración que existen salvedades que veremos más adelante. 
En este sentido se puede apreciar que el reconocimiento al derecho a la presunción de inocencia va en concordancia al Pacto Internacional de Derechos Civiles y Políticos, el cual establece que "Toda persona acusada de un delito tiene derecho a que se presuma su inocencia mientras no se pruebe su culpabilidad conforme a la ley" (Art.14. 2, del PIDCP.). De igual modo, la Convención Americana de Derechos Humanos determina que "Toda persona inculpada de delito tiene derecho a que se presuma su inocencia mientras no se establezca legalmente su culpabilidad. Durante el proceso, toda persona tiene derecho, en plena igualdad, a las siguientes garantías mínimas que enlistan el tratado..." (Art. 8.2. de la CADH.). Por lo tanto, la normativa procesal penal se alineó a los estándares internacionales de derechos humanos, se advierte pues que se debe suponer la inocencia hasta que la culpabilidad no se establezca de manera legal.

Existían una serie de rasgos inquisitivos enquistados que era necesario erradicar, entre ellos, el poder el Fiscal, debido a que la persona imputada debía mostrar su inocencia. De manera muy positiva, con la aprobación de este sistema acusatorio está que la carga de la prueba fue invertida; por tanto, corresponde al Ministerio Público probar la culpabilidad de la persona imputada ${ }^{3}$.

Al respecto Ortega Ruiz (2003) apunta que la presunción de inocencia se basa en dos principios claves: primero, el de la libre valoración de la prueba, que corresponde efectuarla a jueces y tribunales (el ejercicio de la potestad jurisdiccional en todo tipo de procesos, juzgando y haciendo ejecutar lo juzgado, según las normas de competencia y procedimiento que las mismas establezcan); segundo, para desvirtuar esta presunción de inocencia es preciso que se den medios de prueba válidos y lícitamente obtenidos utilizados en el juicio oral, dando siempre lugar a la defensa del acusado.

Por el hecho de no atender los principios señalados y ante la mínima presencia de hechos delictivos, se cae en la reprochable situación de optar por privar de la libertad a la persona, El significado de la coerción personal del imputado, según Alfredo Vélez Mariconde (2004) corresponde a la "restricción o limitación que se impone a su libertad (la del imputado) para asegurar la consecución de los fines del proceso: la averiguación de la verdad y la aplicación de la ley penal". Existen muchos factores que influyen en la tendencia de acudir a la prisión preventiva sin

3 Es necesario tener en consideración que las presunciones de culpabilidad y de inocencia se confrontan en el proceso; lo cual puede llevar a ponderar si se debe restringir el derecho a la intimidad, a la libertad, a la seguridad personal, al patrimonio, etc. con el fin de evitar mayores riesgos; incluso, mayor actividad delictiva. Pero debe ser por las causas que determine la norma y conforme al procedimiento penal establecido por ésta. 
evaluar el riesgo que pudiera llegar a existir, en ciertos casos, cuando han tenido repercusión en la sociedad y medios de comunicación poco serios han seguido un proceso paralelo. También existe la inercia en las decisiones judiciales en cuanto a comparación de los hechos delictivos y la imposición de la medida cautelar, el riesgo de fuga que se puede llegar a presumir, sin realizar ningún tipo de evaluación, y el recurso al uso de la prisión como política criminal con el fin de "mantener" la tranquilidad de los ciudadanos (Sanz Mulas, 2017).

Ante la mera sospecha de la comisión del delito, la privación de libertad conlleva un efecto perverso, esto en virtud de que tiene consecuencias más severas debido a la afectación en su persona: tan solo, el estigma que se presenta por haber estado recluido en un centro carcelario.

Dado que:

(...) la detención de una persona sin condena que declare su culpabilidad constituye una gravísima afectación al estado de inocencia y la libertad ambulatoria de las personas, y como tal debe ser interpretada como medida excepcional, y solo puede ser utilizada a los fines del proceso. (Pinto, 2007)

Por lo tanto, es mediante razonamientos convincentes, testigos o a través del contenido que arroje el informe de evaluación del riesgo, en el que se respalde que la prisión debe ser justificada, necesaria y proporcional a los hechos ocurridos.

Sin realizar este ejercicio de valoración, el uso de la presión preventiva se convierte en una forma de adelantar una pena, cuando no se tiene la certeza de culpabilidad. Además, la práctica como medida de política criminal, por la que se encarcela pues el aparato de justicia está mostrando debilidad para aprehender, justificar o imponer otra medida, se convierte en una situación preocupante en cuanto a la fortaleza en la administración de justicia. Lo cual ha traído como consecuencia que, en la actualidad, vaya al alza el incremento de catálogos de delitos que llevan prisión preventiva oficiosa prevista bajo mandato constitucional.

\section{La reforma del artículo 19 constitucional en 2011}

Mediante reforma constitucional, en el año 2011, se limitó la solicitud prisión preventiva del Ministerio público para que se aplique de manera excepcional, solo cuando otras de las medidas cautelares (trece) no sean suficientes para garantizar los fines clásicos de su justificación como son la presencia del imputado en el juicio, el desarrollo de la investigación, la protección de la víctima, de los 
testigos o de la comunidad, así como cuando el imputado estuviera siendo procesado o hubiera sido sentenciado previamente por la comisión de un delito doloso.

Al margen de esta decisión, el legislador atribuyó al juez la imposición de ordenar la prisión preventiva de manera oficiosa para delitos como delincuencia organizada, homicidio doloso, violación, secuestro, trata de personas, delitos cometidos con medios violentos como armas y explosivos, así como delitos graves que determine la ley en contra de la seguridad de la nación, el libre desarrollo de la personalidad y de la salud.

Se tomaron como justificación elementos como la presencia de violencia en la forma de ejecutar hechos delictivos, como los de la delincuencia organizada, los cometidos con medios violentos como armas y explosivos, los delitos graves relacionados con la seguridad de la nación (entre estos están la traición a la patria, espionaje, motín, financiamiento del terrorismo; todos estos son entendidos por el legislador mexicano como una justificación que evade por completo la posibilidad de que se imponga otra medida cautelar que no sea la prisión preventiva.

El temor de la espera del proceso con otras medidas donde exista la libertad provisional no es tan bien tomado por la ciudadanía. Aunado a ello, la desconfianza en las instituciones y los problemas de impunidad y corrupción se conciben como una justificación, por lo que, se refiere a corrupción, tras la reforma constitucional en materia de anticorrupción en 2015, el 18 de julio de 2016 se aprobó la Ley del Sistema Nacional de Anticorrupción, sin embargo, la Fiscalía Especializada en materia de delitos relacionados con hechos de corrupción, como órgano con autonomía técnica y operativa para investigar y perseguir los hechos que la ley considera como delitos por hechos de corrupción, estuvo acéfala hasta febrero de 2019, al punto de que se nombró a una persona para ocupar el cargo. En cuanto a la impunidad, el nivel es muy elevado, el $99.2 \%$ de los casos quedan impunes

Aunado a ello, "los delitos no denunciados, se mantiene en un nivel muy alto e incluso aumentó casi un punto porcentual en dos años al pasar de $92.8 \%$ a $93.7 \%$ (ENVIPE, INEGI). Esto confirma que los mexicanos siguen sin tener confianza en sus instituciones de seguridad y justicia para denunciar los delitos de los cuales fueron víctimas" Índice global de impunidad igi-mex (Le Clercq Ortega y Sánchez Lara, 2018).

En muchas ocasiones, la ciudadanía tiene desconfianza en el operador de justicia, la ausencia de investigación o que esta no se haga de manera adecuada, la ausencia de datos o de la contratación de los mismos, así como la falta de personal policial en algunas entidades federativas, personal de servicios periciales e 
insumos que requieren de manera general los operadores, son elementos que no han contribuido a que se deje atrás esta práctica tan desafortunada.

Definitivamente, se ha optado por el constreñimiento de los derechos de las personas que se ven involucradas en un proceso de carácter penal.

\section{La reforma del artículo 19 constitucional en el 2019}

La modificación del precepto constitucional numeral 19 fue bastante discutida, opinaron legisladores, políticos, académicos, asociaciones civiles de todo el país en la Cámara de diputados, en programas de televisión con gran difusión por parte de los medios de comunicaciones, por los efectos tan importantes que esto acarreaba; se trató de incrementar el catálogo de delitos penales para imponerles, de manera automática, prisión preventiva; cabe apuntar que la inseguridad pública alimentó, en gran medida, esta decisión.

Además de los delitos incluidos en la reforma constitucional de 2011, se sumaron, en el 2019 a la lista del citado precepto, delitos como abuso o violencia sexual contra menores, feminicidio, robos en casas de habitación, uso de programas sociales con fines electorales, corrupción (delitos de enriquecimiento ilícito y ejercicio abusivo de funciones), robo al transporte de carga en cualquiera de sus modalidades.

También, se añadieron delitos en materia de hidrocarburos, petrolíferos o petroquímicos; desaparición forzada de personas y desaparición cometida por particulares. En materia de armas de fuego y explosivos de uso exclusivo del Ejército, la Armada y la Fuerza Aérea, la inclusión de todos estos ilícitos fue aprobada por la Senado, la Cámara de Diputados y 20 entidades federativas y las Ciudad de México, la Cámara Baja aprobó con mayoría calificada la reforma constitucional para incrementar el número de delitos en relación de prisión preventiva oficiosa (Cámara de Diputados, 2019).

Como se puede apreciar, la elección de delitos sigue la misma línea relacionada con la reforma previa, elementos en la forma de ejecución del hecho delictivo como la violencia se refleja con la presencia del delito de feminicidio, delito cuya característica es la de un delito agravado debido a la violencia contra la mujer por razones de género para la comisión del mismo.

Por su parte, sorprende que, por el uso de programas sociales con fines electorales, la necesidad de prisión preventiva no se entiende mucho en cuanto a la proporcionalidad que debe de tener la imposición de la medida, teniendo en consideración que existen otras 13 medidas cautelares que pudieran imponerse. 
Se arguye que, durante el periodo de comicios, se verá un incremento importante en la imposición de prisión preventiva debido a que, dependiendo de la zona y la situación que le rodea, estas sean más o menos pacíficas.

En cuanto a los delitos relacionados con hidrocarburos y otros derivados del petróleo, en la actualidad, la problemática actual es muy evidente, así como las medidas del Gobierno entrante, en contra de las formas de comisión de este ilícito (Ley federal para prevenir y sancionar los delitos cometidos en materia de hidrocarburos, 2018. $)^{4}$, y la participación en él. Sin embargo, ante situaciones de tal magnitud, la prisión preventiva, como mera justificación para detener esto, no es suficiente; se requiere toda una planeación en cuanto a la prevención de este tipo de delito, cuya comisión está tan extendida en el país.

La cuestión de delitos de carácter sexual hacia menores de edad sigue presente. $\mathrm{Al}$ igual que la reforma pasada, parece que la posibilidad de que agresores queden en libertad justifique el uso de oficio de la prisión preventiva en lugar de continuar con el reforzamiento en la actuación de los operadores de justicia de todos los niveles.

\section{Repercusión de los cambios normativos en la población penitenciaria}

Ante la excepcionalidad para imponer la prisión preventiva, era lógico que la población penitenciaria se redujera en la práctica. La reforma constitucional en materia de justicia penal y seguridad pública se basó en cuestiones como la despresurización de las prisiones.

Para determinar los resultados al respecto se hizo un análisis sobre la población penitenciaria en las 32 entidades federativas (31 estados y la Ciudad de México (en adelante $C D M X)$ ) para conocer si durante el periodo de enero de 2013 a junio de 2018 efectivamente, como estaba previsto, se redujo la prisión de manera preventiva. Se analizaron las siguientes circunstancias:

a) Determinar si se redujo altamente, considerablemente o levemente, el número de personas en prisión preventiva y determinar en qué ciudades.

4 Estas pueden ser, sustracción, aprovechamiento, compra, enajenación, recibimiento, adquisición, comercialización o negociación, resguardo, transportación, almacenamiento, distribución, posesión, suministro u ocultación, alteración de hidrocarburos, petrolíferos o petroquímicos, de ductos, vehículos, equipos, instalaciones o activos, sin derecho y sin consentimiento de asignatarios, contratistas, permisionarios, distribuidores o de quien pueda disponer de ellos con arreglo a la ley. 
b) Se aumentó altamente, considerablemente o levemente el número de presos bajo medida cautelar preventiva en algunas entidades y conocer cuáles son estas.

c) Si no se presentó ningún cambio en cuanto al número de estas.

Para la determinación de altamente, considerablemente y levemente se utilizó la siguiente base: altamente varía de 501 a 15 000, considerablemente es de 301 a 500 y levemente de 50 a 300 . A continuación, se hace el análisis teniendo en consideración los datos obtenidos en las entidades mencionadas conforme al último Informe de Gobierno ya citado.

\section{Reducción del número de presos bajo medida cautelar preventiva en las siguientes entidades:}

\section{a) Reducción significativa \\ i. Ciudad de México}

En 2013, la Ciudad de México tenía una cifra absoluta de 40637 privados de libertad (3 789 del fuero federal y 36848 del fuero común); mientras que, para junio de 2018, la cifra era de 27007 (3 064 del fuero federal y 23943 del fuero común). En cifras absolutas, en el último lustro, la capital mexicana bajó el número de personas privadas de la libertad a 13630 (725 del fuero federal y 12905 del fuero común).

Durante esos años, la Ciudad de México ha mostrado una tendencia a la baja. En el 2014, la cifra de personas privadas de la libertad era de 39279 (3 764 del fuero federal y 35515 del fuero común); en 2015, descendió a 36142 (3 688 del fuero federal y 32454 del fuero común); en 2016, bajo aún más a 30987 (3 396 del fuero federal y 27591 del fuero común); y, en 2017, la cifra alcanzó los 27754 privados de la libertad (3 208 del fuero federal y 24546 del fuero común).

En síntesis, en el último lustro, la capital de la República Mexicana ha mostrado una tendencia a la baja, teniendo su nivel más bajo en junio de 2018 .

\section{ii. Baja California}

En el año de 2013, Baja California tenía una cifra absoluta de 16560 privados de la libertad (3 112 del fuero federal y 13448 del fuero común); mientras que, para junio de 2018, la citada entidad federativa tuvo un total de 11745 privados de la libertad (1 904 del fuero federal y 9841 del fuero común). En cifras absolutas, en 
el último lustro, Baja California ha mostrado un descenso en su población penitenciaria de 4815 (1 208 del fuero federal y 1703 del fuero común).

Entre 2013 y 2018, Baja California ha mostrado, preponderantemente, un descenso continuo en su población penitenciaria: en 2014, la cifra descendió a 16264 (3 054 del fuero federal y 13210 del fuero común); en 2015, la cifra bajó a 15 658 (2 980 del fuero federal y 12678 del fuero común); en 2016, la cifra rondó los 12894 personas (2 272 del fuero federal y 10622 del fuero común); mientras que, en 2017, la cifra bajó a 11608 personas (2 033 del fuero federal y 9575 del fuero común).

Las cifras preliminares que se tienen en 2018 indican que, en junio de 2018, Baja California tuvo un leve ascenso en su población penitenciaria: pasó de 11608 privados de la libertad (2 033 del fuero federal y 9575 del fuero común) a 11,745 (1 904 del fuero federal y 9841 del fuero común), mostrando una alza en su población del fuero común.

En términos generales, Baja California ha tenido un descenso significativo en su población penitenciaria, a pesar del breve repunte mostrado en junio de 2018.

\section{iii. Sonora}

En 2013, Sonora tenía un total de 12282 privados de la libertad (1 597 del fuero federal y 10685 del fuero común); mientras que, en 2018, el total de su población penitenciaria se ubicó en 7503 (511 del fuero federal y 6992 del fuero común). En cifras absolutas, la citada entidad norteña logró bajar el número de privados de la libertad de manera considerable: tuvo 4779 privados de la libertad menos (1 086 del fuero federal y 3693 del fuero común).

Entre esos años, la tendencia de su población penitenciaria se mantuvo a la baja: en 2014, tenía 11424 privados de la libertad (1 253 del fuero federal y 10171 del fuero común); en 2015, la cifra bajó a 10736 (1,062 del fuero federal y 9674 del fuero común); en 2016, la cifra absoluta descendió a 8218 (738 del fuero federal y 7480 del fuero común); y, en 2017, la cantidad de privados de la libertad sumaba un total de 7823 (567 del fuero federal y 7256 del fuero común).

En suma, se puede decir que Sonora, en el último lustro, ha hecho un gran trabajo en su sistema penitenciario: logró bajar su cantidad de privados de la libertad en poco más de un tercio. 


\section{iv. Jalisco}

Jalisco es una entidad federativa que, en 2013, tenía una cifra de 17195 personas (3 287 del fuero federal y 13908 del fuero común); mientras que, para junio de 2018, dicho estado tuvo un descenso en su población penitenciaria de 3071 privados de la libertad (286 del fuero federal y 2785 del fuero común): la cifra total de privados de la libertad, en 2018, era de 14124 (3 001 del fuero federal y 11 123 del fuero común).

Sin embargo, el descenso no fue continuo, sino que tuvo sus altibajos: en 2014, la cifra de personas ascendió a 18225 (3,461 del fuero federal y 14764 del fuero federal). Afortunadamente, desde 2015, el descenso ha sido continuo: en ese año, Jalisco tenía una cifra total de 17549 privados de la libertad (3 589 del fuero federal y 13960 del fuero común); mientras que, en el siguiente año, la cifra descendió a 15741 (3,289 del fuero federal y 12452 del fuero común). En 2017, la cifra descendió aún más: tal estado acogió, en su sistema penitenciario, a un total de 14507 personas (3 065 del fuero federal y 11442 del fuero común).

En conclusión, se pude decir que Jalisco, en el último lustro, ha sido un estado que ha mantenido una tendencia a la baja; pese al altibajo que tuvo en 2015.

\section{v. Chiapas}

En 2013, Chiapas tenía una población penitenciaria de 6686 privados de la libertad (616 del fuero federal y 6070 del fuero común); mientras que, en junio de 2018, la cifra descendió a 3750 personas (136 del fuero federal y 3614 del fuero común). En cifras absolutas, en el último lustro, Chiapas bajó su población penitenciaria en poco menos de la mitad: 2936 privados de la libertad (480 del fuero federal y 2456 del fuero común).

Dicho descenso no fue continuo: en 2014, la cifra de población penitenciaria ascendió a 6695 (533 del fuero federal y 6162 del fuero común). Sin embargo, los siguientes años sí muestran unas cifras a la baja: en 2015, Chiapas tuvo 5,997 personas en prisión (395 del fuero federal y 5602 del fuero común); en 2016, 4 560 (126 del fuero federal y 4434 fuero común); y, en 2017, los privados de la libertad fueron 4006 (143 del fuero federal y 3863 del fuero común).

En síntesis, en el último lustro, Chiapas muestra una tendencia hacia la baja; teniendo su nivel más bajo en junio de 2018. 


\section{vi. Sinaloa}

En 2013, Sinaloa tenía una población penitenciaria de 6954 (1,237 del fuero federal y 5717 del fuero común); mientras que, en junio de 2018, dicha entidad federativa redujo considerablemente su cifra tenía 4700 privados de la libertad (963 del fuero federal y 3737 del fuero común). En cifras absolutas, la entidad del noroeste del país logró descender el total de sus personas en 2254 (274 del fuero federal y 1980 del fuero común).

Entre esos años, tuvo una serie de altibajos: en 2014, la cifra se ubicó en 7647 (1,342 del fuero federal y 6305 del fuero común); en 2015, descendió a 7133 (1 382 del fuero federal y 5751 del fuero común); en 2016, siguió bajando aún más, pues se estableció en 5,518 (1,078 del fuero federal y 4440 del fuero común); y, en 2017, la cifra descendió a 4873 (958 del fuero federal y 3915 del fuero común).

En síntesis, la citada entidad, en el último lustro, ha logrado bajar la cantidad de su población penitenciaria; pese a los altibajos que sufrió entre 2014 y 2015.

\section{vii. Puebla}

En 2013, Puebla tenía una población penitenciaria de 9117 privados de la libertad (533 del fuero federal y 8584 del fuero común); mientras que, para junio de 2018, la citada entidad federativa contaba con un total de 6922 personas (469 del fuero federal y 6453 del fuero común). En cifras absolutas, en el último lustro, la citada entidad federativa logró descender su número de privados de la libertad en 2195 (64 del fuero federal y 2131 del fuero común).

Sin embargo, la tendencia negativa tuvo un pequeño sobresalto en 2014; en ese año, la tasa de personas era de 9550 (537 del fuero federal y 8548 del fue común). Fuera de ese año, la tendencia fue negativa en los siguientes años: en 2015, la cantidad de población penitenciaria era de 9550 personas (537 del fuero federal y 9013 del fuero común); en 2016, la tasa era de 7502 (411 del fuero federal y 7091 del fuero común); y, en 2017, la cifra descendió a su nivel más bajo en el último lustro: 6598 (457 del fuero federal y 6141 del fuero común).

En síntesis, pese al pequeño altibajo que tuvo en 2014, la tendencia sobre población penitenciaria ---en Puebla--- se ha mantenido a la baja. 


\section{viii. Colima}

En 2013, Colima tenía una población penitenciaria de 3613 privados de la libertad (522 del fuero federal y 3091 del fuero común); mientras que, para junio de 2018, la cifra era de 1673 (219 del fuero federal y 1454 del fuero común). En cifras absolutas, Colima ha mostrado, en el último lustro, un descenso ---en su población penitenciaria--- de 1940 personas (303 del fuero federal y 1637 del fuero común).

Sin embargo, el descenso en su población penitenciaria no fue continuo, es decir, hubo un año (2014) en el que aumentó la cifra de privados de la libertad con respecto a 2013; en ese año, hubo 3785 personas (282 del fuero federal y 3503 del fuero común). En los años siguientes, la cifra comenzó a bajar de manera drástica. En 2015, la población penitenciaria era de 2917 (254 del fuero federal y 2663 del fuero común); en 2016, la cantidad de personas en prisión fue de 2 439 (237 del fuero federal y 2202 del fuero común); en 2016, la cifra de personas descendió a 1880 (229 del fuero federal y 1651 del fuero común); y, en 2017, la cifra absoluta de privados de la libertad fue de 1880 (229 del fuero federal y 1 651 del fuero común).

En suma, el último lustro ha evidencia que Colima ha tenido un descenso en su población penitenciaria significativo; teniendo su nivel más bajo en junio de 2018.

\section{ix. Veracruz}

En 2013, Veracruz tenía una población penitenciaria de 7944 privados de la libertad (211 del fuero federal y 7733 del fuero común); mientras que, para junio de 2018, la cantidad de personas privadas de su libertad descendió a 6781 (203 del fuero federal y 6578 del fuero común). En cifras absolutas, la citada entidad federativa logró reducir su número de personas en 1163 (7 del fuero federal y 1 155 del fuero común).

Entre 2013 y 2018, Veracruz ha tenido una tendencia volátil con respecto a su población penitenciaria. En 2014, el número de privados de la libertad era de 8 237 (173 del fuero federal y 8064 del fuero común); en 2015, la cifra bajó a 7532 (177 del fuero federal y 7355 del fuero común); en 2016, el número de personas se redujo a 6999 (183 del fuero federal y 6816 del fuero común); y, en 2017, la cifra se estableció en 6838 (201 del fuero federal y 6637 del fuero común). 
En suma, se puede afirmar que Veracruz ha logrado descender el número de su población penitenciaria; teniendo, en el último lustro, a 2018 como el año en el que su cifra estuvo más baja.

\section{x. Guerrero}

En 2013, Guerrero tenía una cifra de 5853 privados de la libertad (1 055 del fuero federal y 4798 del fuero común); mientras que, para junio de 2018, la citada entidad tuvo una cifra de 4384 (787 del fuero federal y 3597 del fuero común). En cifras absolutas, en el último lustro, la entidad federativa en comento bajó su cifra de personas en 1469 (268 del fuero federal y 1,201 del fuero común).

Durante esos años, Guerrero tuvo una tendencia hacia la baja. En 2014, la cifra de privados de la libertad era de 5692 (947 del fuero federal y 4745 del fuero común); en 2015, bajó a 5347 (905 del fuero federal y 4442 del fuero común); en 2016, descendió aún más: se colocó en 4862 (844 del fuero federal y 4018 del fuero común); y, en 2017, la población penitenciaria total era de 4482 (756 del fuero federal y 3726 del fuero común).

En síntesis, Guerrero ---en el último lustro--- ha sido de las entidades federativas que ha tenido una tendencia a la baja; teniendo su cifra más baja en junio de 2018.

\section{xi. Nuevo León}

En 2013, Nuevo León tenía un total de 8727 privados de la libertad (1 492 del fuero federal y 7235 del fuero común); cosa que, para junio de 2018, había cambiado; en esa fecha, la citada entidad federativa ostentaba un total de 7,305 personas privadas de la libertad (1 307 del fuero federal y 5998 del fuero común). En cifras absolutas, el estado norteño ---en menos de un lustro--- disminuyó su población penitenciaria en 1422 personas ( 185 del fuero federal y 1237 del fuero común).

Entre esos años, Nuevo León ha tenido una serie de altibajos que no permiten establecer una tendencia clara. En 2014, la entidad federativa contaba con 8732 (1,640 del fuero federal y 7092 del fuero común); mientras que, en 2015, tenía 7,909 (1 774 del fuero federal y 6135 del fuero federal). En 2016, la cantidad de privados de la libertad descendió considerablemente: 7200 (1,551 del fuero federal y 5,649 del fuero común); mientras que, en 2017, la cifra quedó casi igual: 7,208 (1,350 del fuero federal y 5,858 del fuero común). 
En síntesis, en este último lustro, Nuevo León logró bajar su cifra; sin embargo, lo ha hecho mediante un proceso de muchos altibajos.

\section{xii. San Luis Potosí}

En 2013, la entidad potosina tuvo una población penitenciaria de 3480 privados de la libertad; 1155 más que en junio de 2018; en ese período, la citada entidad federativa tuvo un total de 2325 de personas (192 del fuero federal y 2,133 del fuero común). Así, en el último lustro, San Luis Potosí ha logrado descender su cantidad de privados de la libertad; a costa de sufrir un ligero ascenso en 2014; en ese año, tal estado tenía una población penitenciaria de 3549 personas (129 del fuero federal y 3420 del fuero común).

En los años posteriores, San Luis Potosí ha mostrado una tendencia a la baja en su población penitenciaria. En 2015, la cantidad total de privados de la libertad era de 3,026 (175 del fuero federal y 3031 del fuero común); en 2016, la cifra cerró en 2572 (184 del fuero federal y y 2388 del fuero común); y, en 2017, el total de personas privadas de libertad se ubicó en 2369 ( 187 del fuero federal y 2182 del fuero común).

En suma, San Luis Potosí ha logrado, en el último lustro, bajar la cantidad de población penitenciaria y tuvo su cifra más baja en junio de 2018 .

\section{xiii. Tamaulipas}

Tamaulipas es una entidad federativa que, en el año de 2013, tenía una población penitenciaria de 6005 privados de la libertad (1,081 del fuero federal y 4924 del fuero común); 1087 más que en junio de 2018; en esta última fecha, la entidad del noreste tenía alrededor de 4918 personas privadas de su libertad (1 064 del fuero común y 3854 del fuero federal).

Entre 2013 y junio de 2018, la cantidad de presos se ha mantenido a la baja; pese al ligero repunte que hubo en 2014 y 2015: en 2014, la cantidad era de 6482 ( 1,157 del fuero federal y 5325 del fuero común); en 2015, la cifra ascendió a 6716 (1,182 del fuero federal y 5534 del fuero común). Empero, como ya se apuntó, las cifras comenzaron a bajar desde 2016; en este año, la cantidad de presos era de 5724 (1 158 del fuero federal y 4566 del fuero común); mientras que, en 2017, la cantidad bajó aún más a 5058 (1,092 del fuero federal y 3966 del fuero común). 
En suma, se puede decir que Tamaulipas, pese a los altibajos, ha podido descender su cifra de población penitenciaria en el último lustro.

\section{xiv. Tabasco}

En 2013, Tabasco tenía una población penitenciaria de 4888 presos (208 del fuero federal y 4680 del fuero común); 1059 más que en junio de 2018. En esta última fecha, la cifra total de privados de la libertad que tenía la citada entidad federativa era de 3829 ( 84 del fuero federal y 3745 del fuero común).

Entre esos años, Tabasco ha mantenido, a la baja, la tendencia en su población penitenciaria: en 2014, la cifra total de era de 4 543; en 2015, el indicador se estableció en 4213 (135 del fuero federal y 4078 del fuero común); en 2016, la cifra descendió a 3898 (129 del fuero federal y 3769 del fuero común); y, en 2017, la cantidad alcanzó su número más bajo: 3746 privados de la libertad ( 83 del fuero federal y 3663 del fuero común).

En términos generales, pese al repunte del último dato, recabado en junio de 2018, se puede decir que ---en el último lustro--- Tabasco ha logrado descender su cifra de población penitenciaria; tuvo su cifra más baja en el año de 2017.

\section{xv. Nayarit}

En 2013, el estado de Nayarit tenía una población penitenciaria de 3075 presos ( 212 del fuero federal y 2863 del fuero federal); mientras que, para junio de 2018, la cifra de privados de la libertad de la entidad descendió en poco más de 1 000: en ese año, la entidad federativa tuvo 2060 privados de la libertad ( 76 del fuero federal y 1984 del fuero común), para ser exactos. En ese sentido, en cerca de un lustro, la cantidad total de privados de la libertad ---en el estado de Nayarit--- bajó en cerca de una tercera parte.

Sin embargo, entre esos años, la tendencia negativa que tuvo esa entidad federativa sufrió algunos altibajos. En 2014, su población penitenciaria era de 3344 (191 del fuero federal y 3153 del fuero común); mientras que en 2015 el total de personas privadas de la libertad fue de 3490 (199 del fuero federal y 3291 del fuero común). Empero, a partir de 2016, la tendencia se tornó a la baja; en ese año, Nayarit tuvo un total de 2847 privados de la libertad (134 del fuero federal y 2713 del fuero común); mientras que en 2017 la cifra bajó a 2255 (88 del fuero federal y 2167 del fuero común). 
En suma, Nayarit, al igual que muchas otras entidades federativas, logró reducir el número de personas en prisión; sin embargo, para que eso pasara, tuvieron que darse algunos altibajos.

\section{xvi. Yucatán}

En 2013, Yucatán tenía una población penitenciaria de 2357 privados de la libertad (162 del fuero federal y 2195 del fuero común); 1023 más que en junio de 2018: en ese período, la citada entidad federativa tenía una cifra total de 1334 presos (84 del fuero federal y 1250 del fuero común). En términos generales, Yucatán ha logrado descender su población penitenciaria de manera considerable.

En ese lustro, el número de privados de la libertad ha tenido una tendencia a la baja. En 2014, la cantidad era de 1856 (159 del fuero federal y 1,697 del fuero común); en 2015, la cifra era de 1581 (160 del fuero federal y 1421 del fuero común); en 2016, la cifra absoluta fue de 1453 privados de la libertad (97 del fuero federal y 1,356 del fuero común); y, en 2017, la cifra se ubicó en 1386 (92 del fuero federal y 1294 del fuero común).

En suma, Yucatán es de las pocas entidades federativas que, en el último lustro, ha tenido una tendencia a la baja, sin ningún sobresalto, en su población penitenciaria.

\section{xvii. Oaxaca}

En 2013, la entidad federativa que se ubica en el sureste mexicano tenía una población penitenciaria de 4316 privados de la libertad (702 del fuero federal y 3 614 del fuero común); mientras que, para junio de 2018, la citada entidad tenía un total de 3526 privados de la libertad (316 del fuero federal y 3210 del fuero común). En cifras absolutas, en el último lustro, la citada entidad federativa logró descender su número de presos en 835 (386 del fuero federal y 404 del fuero común).

En ese lustro, Oaxaca no ha tenido una tendencia clara, es decir, ha pasado por una serie de altibajos que no impide marcar una orientación clara. En 2014, tuvo una población penitenciaria de 4393 (774 del fuero federal y 3619 del fuero común); en 2015, la cifra se elevó a 4400 (716 del fuero federal y 3684 del fuero común); en 2016, descendió a 3923 (414 del fuero federal y 3509 del fuero común); en 2017, bajó aún más a 3,572 (340 del fuero federal y 3232 del fuero común). 
En síntesis, pese a la inexistencia de una tendencia marcada, Oaxaca ha logrado bajar sus cifras de población penitenciaria y tuvo, en el último lustro, a 2018 como el año en el que menos privados de la libertad ha habido.

\section{xviii. Coahuila}

En 2013, Coahuila tenía una cifra absoluta de 2654 presos ( 25 del fuero federal y 2629 del fuero común); mientras que, para junio de 2018, la citada entidad federativa tuvo un total de 1958 ( 37 del fuero federal y 1921 del fuero común). En cifras absolutas, Coahuila ha mostrado, en el último lustro, un descenso significativo en su población penitenciaria de 733 privados de la libertad.

Sin embargo, entre esos años, dicho descenso comenzó a ser notorio a partir de 2016. Afirmo esto en tanto que, en 2014 y 2015, la población penitenciaria tuvo un ascenso con respecto a 201. En el primero de esos años, se registró un total de 3047 privados de la libertad (50 del fuero federal y 2997 del fuero común); mientras que, en el segundo, la cifra era de 3024 (46 del fuero federal y 2978 del fuero común). Ya para 2016, la cifra mostró un descenso significativo: se registró un total de 2229 (46 del fuero federal y 2,183 del fuero común). En lo que respecta a 2017, la cifra descendió aún más: 2041 (27 del fuero federal y 2004 del fuero común).

En términos generales, en el último lustro, Coahuila ha mostrado un descenso significativo en su población penitenciaria; alcanzando su nivel más bajo en junio de 2018.

\section{xix. Quintana Roo}

En 2013, Quintana Roo tenía una población penitenciaria de 3605 privados de la libertad (183 del fuero federal y 3,736 del fuero común); mientras que, para junio de 2018, la citada entidad tuvo un considerable descenso: la cifra se ubicó en 3 007 presos (219 del fuero federal y 2,788 del fuero común). En términos absolutos, la cantidad de personas privadas de la libertad descendió en 598 .

Entre esos años, hubo una volatilidad en la tendencia. En 2014, la cifra de privados de la libertad se ubicó en 3991 (255 del fuero federal y 3,736 del fuero común); mientras que, en 2015, la cifra ascendió a 4027 (254 del fuero federal y 3773 del fuero común). Así, en esos dos años, hubo una tendencia a la alza. Sin embargo, entre 2016 y 2017, la cifra de presos bajó estrepitosamente. En 2016, la cifra rondó los 3524 privados de la libertad (206 del fuero federal y 3318 del 
fuero común); mientras que, en 2017, la cantidad de privados de la libertad fue de 3150 (221 del fuero federal y 2929 del fuero común).

Grosso modo, Quintana Roo, en el último lustro, ha logrado descender el número de sus presos; sin embargo, lo ha hecho a costa de tener una tendencia con altibajos.

\section{$x x$. Baja California Sur}

En 2013, Baja California Sur tenía una cifra absoluta de 1804 presos (272 del fuero federal y 1532 del fuero común); mientras que, para junio de 2018, la citada entidad federativa tuvo un total de 1245 privados de la libertad (230 del fuero federal y 1015 del fuero común). En cifras absolutas, Baja California sur ha mostrado, en el último lustro, un descenso en su población penitenciaria de 559 (42 del fuero federal y 517 del fuero común).

Sin embargo, entres esos años, dicho descenso comenzó a ser notorio hasta 2016. Afirmo lo anterior porque, en 2014 y 2015, la cifra de presos superó la que se tenía en 2013: 1986 (321 del fuero federal y 1665 del fuero común) en 2014 y 1842 (249 del fuero federal y 1593 del fuero común). Ya para 2106, hubo un descenso considerable en la cifra absoluta de privados de la libertad: 1550 (268 del fuero federal y 1282 del fuero común). Lo mismo se puede decir de 2017: 1 266 (268 del fuero federal y 1593 del fuero común).

En síntesis, Baja California Sur ha logrado, en el último lustro, un descenso en su población penitenciaria; alcanzando su cifra más baja en Junio de 2018.

\section{b) Reducción considerable ${ }^{5}$}

\section{i. Querétaro}

En 2013, la entidad queretana tuvo una población penitenciaria de 2546 presos (254 del fuero federal y 2,292 del fuero común); mientras que, en junio de 2018, tuvo un descenso de 362 ( 88 del fuero federal y 274 del fuero común): en ese año, la población penitenciaria se ubicó en 2184 (166 del fuero federal y 2018 del fuero común).

Entre esos años, ha habido una tendencia a la baja y tuvo un ligero ascenso en el último par de años. En 2014, la cifra absoluta de personas privadas de la libertad era de 2420 (254 del fuero federal y 2 292); en 2015, la cifra bajó a 2247 (209

5 Se toma en cuenta que la reducción sea 301 a 500 durante el periodo comprendido entre 2013 y 2018. 
del fuero federal y 2038 del fuero común); en 2016, la cifra se ubicó en 2040 (161 del fuero federal y 1879 del fuero común); mientras que, en 2017, la cifra ascendió a 2114 (174 del fuero federal y 1940 del fuero común).

En suma, Querétaro ha logrado, en el último lustro, descender el número de personas privadas de la libertad; sin embargo, lo ha hecho con una tendencia a la alza en el último par de años.

\section{c) Reducción leve ${ }^{6}$}

\section{i. Tlaxcala}

En 2013, Tlaxcala tenía una población penitenciaria de 826 privados de la libertad (109 del fuero federal y 717 del fuero común); mientras que, en junio de 2018, la citada entidad tenía una cifra total de 578 presos (87 del fuero federal y 491 del fuero común). En cifras absolutas, en el último lustro, la citada entidad federativa bajó su población penitenciaria en 248 presos (22 del fuero federal y 226 del fuero común).

Entre esos años, Tlaxcala ha mostrado una tendencia con algunos altibajos. En 2014, su cifra total de privados de la libertad se ubicó en 879 (126 del fuero federal y 753 del fuero común); en 2015, ascendió a 882 (99 del fuero federal y 783 del fuero común); en 2016, bajó estrepitosamente a 608 presos (72 del fuero federal y 629 del fuero común); y, en 2017, la cifra se estableció en 608 (62 del fuero federal y 546 del fuero común).

En conclusión, se puede decir que, en el último lustro, Tlaxcala logró bajar la cifra de su población penitenciaria; a pesar de los altibajos.

\section{ii. Aguascalientes}

En 2013, Aguascalientes tenía una cifra absoluta de 1380 privados de la libertad (217 del fuero federal y 1163 del fuero común); mientras que, para junio de 2018, la citada entidad federativa tuvo un total de 1142 privados de la libertad (133 del fuero federal y 1009 del fuero común). En cifras absolutas, en el último lustro, Aguascalientes ha tenido un descenso en su población penitenciaria de 238 presos (84 del fuero federal y 154 del fuero común).

Cabe precisar que, dicho descenso se notó a partir de $2016 \mathrm{~m}$ debido a que durante los años 2014 y 2015, la cifra de personas privadas de libertad superó el número

6 Se toma en cuenta que la reducción sea 50 a 300 durante el periodo comprendido entre 2013 y 2018. 
que se tenía en 2013: 1551 (253 del fuero federal y 1298 del fuero común) en 2014 y 1632 (248 del fuero federal y 1384 del fuero común) en 2015.

Ya para 2016, la cifra total, descendió a 1292 (160 del fuero federal y 1132 del fuero común); mientras que, en 2017, la cifra absoluta de población penitenciaria bajó aún más: 1170 (135 del fuero federal y 1035 del fuero federal).

En términos generales, Aguascalientes ha tenido, en el último lustro, un descenso en su población penitenciaria y alcanzó su cifra más baja en junio de 2018.

\section{iii. Campeche}

En 2013, Campeche tenía una cifra absoluta de 1419 privados de la libertad (137 del fuero federal y 1282 del fuero común); mientras que, para junio de 2018, dicha entidad federativa ostentó un total de 1307 presos (100 del fuero federal y 1207 del fuero común). Si se comparan esos dos años, puede argüirse que Campeche ha mostrado un descenso de 112 presos ( 37 del fuero federal y 75 del fuero común).

Sin embargo, entre esos años, dicho descenso comenzó a ser notorio a partir de 2017. Y es que, en 2014 y 2015, la cifra se elevó con respecto a la que se tenía en 2013. En 2014, la cifra ascendió a 1588 privados de la libertad (181 del fuero federal y 1407 del fuero común); mientras que, en 2015, la cifra descendió con respecto a 2014, aunque no con respecto a lo que se tenía dos años antes: 1,528 (187 del fuero federal y 1341 del fuero común). Ya para 2016, la cifra volvió a rondar los 1418 (144 del fuero federal y 1274 del fuero común); mientras que, para 2017, la cifra descendió a los 1367 (116 del fuero federal y 1251 del fuero común).

En términos generales, Campeche, en el último lustro, ha mostrado un pequeño descenso en su población penitenciaria; alcanzando su nivel más bajo en junio de 2018 .

\section{iv. Morelos}

En 2013, Morelos tenía una población penitenciaria de 3499 privados de la libertad (669 del fuero federal y 2830 del fuero común); mientras que, en junio de 2018, la cifra descendió a 3373 (479 del fuero federal y 2894 del fuero común). En este sentido, se puede ver que, en el último lustro, la cantidad de presos ha tenido un ligero descenso de 126 privados de la libertad.

Entre esos años, Morelos ha mostrado una tendencia de altibajos: en 2014, la cifra total de presos era de 3706 (841 del fuero federal y 2865 del fuero común); en 2015 , la cantidad de presos era de 3,666 (751 del fuero federal y 2,915 del fuero 
común); en 2016, la cifra descendió a 3423 (591 del fuero federal y 2832 del fuero común); y, en 2017, bajó aún más: 3430 privados de la libertad (528 del fuero federal y 2902 del fuero federal).

En síntesis, en el último lustro, Morelos ha tenido un ligero descenso en su población penitenciaria; teniendo, en junio de 2018, su cifra más baja.

\section{d) No se presentó un cambio notable en el número de personas a las que se les impuso prisión de manera preventiva}

\section{v. Michoacán}

En 2013, el estado de Michoacán tenía un total de 4915 privados de la libertad (688 del fuero federal y 4227 del fuero común); mientras que, en junio de 2018, la cifra de presos era casi la misma. En este último año, el número total de presos era de 4929 (631 del fuero federal y 4298 del fuero común).

Entre esos años, la cifra de privados de la libertad ha sido muy volátil. En 2014, la población penitenciaria era de 6420 (762 del fuero federal y 5658 del fuero común); en 2015, la cifra total bajó a 5840 (853 del fuero federal y 4987 del fuero común); en 2016, la cifra bajó aún más a 5000 (942 del fuero federal y 4 058 del fuero común); y, en 2017, la cifra descendió a su menor nivel del último lustro: 4792 (648 del fuero federal y 4144 del fuero común).

En suma, en el último lustro, Michoacán ha tenido una tendencia con muchos altibajos; tuvo su punto más bajo en 2017.

\section{Aumento del número de presos con medidas cautelares preventivas en algunas entidades}

\section{a) Incremento alto \\ i. $\quad$ Estado de México}

En 2013, el Estado de México tenía una cifra absoluta de 19360 privados de la libertad (1 034 del fuero federal y 18326 del fuero común); 8407 (228 del fuero federal y 8179 del fuero común) menos de los que tuvo en junio de 2018: en esa fecha, el total de presos era de 27767 (1 262 del fuero federal y 26505 del fuero común).

A pesar de que el Estado de México fue uno de los estados pioneros en implementar el sistema de justicia penal adversarial, eso no se ha visto reflejado en sus cifras de población penitenciaria. Entre esos años, la tendencia ha tenido altibajos; 
sin embargo, la cantidad de presos se mantiene a la alza. En 2014, la cantidad de privados de la libertad era de 24347 (1,224 del fuero federal y 23123 del fuero común); en 2015, la cifra ascendió a 26864 (1,292 del fuero federal y 25572 del fuero común); en 2016, la cantidad de bajó a 25723 (1,228 del fuero federal y 24 495 del fuero común); y, en 2017, la cifra volvió a ascender: alcanzó los 26874 presos (1 239 del fuero federal y 25635 del fuero común).

En síntesis, el Estado de México, pese a sus leves altibajos, tiene una tendencia a la alza; su punto más alto fue en junio de 2018.

\section{ii. Guanajuato}

En 2013, Guanajuato tenía una cifra absoluta de 4,043 privados de la libertad (565 del fuero federal y 3,478 del fuero común); mientras que, para junio de 2018, la cifra ascendió a 5,107 (336 del fuero federal y 4,771 del fuero común). En cifras absolutas, en el último lustro, dicha entidad federativa elevó su cifra de privados de la libertad a 1,064.

Entre esos años, Guanajuato ha mostrado una tendencia a la alza: en 2014, la cifra de personas privadas de la libertad era de 4,271 (473 del fuero federal y 3,798 del fuero común); en 2015, ascendió a 4,477 (458 del fuero federal y 4,019 del fuero común); en 2016, subió a 4,571 (384 del fuero federal y 4,187 del fuero común); y, en 2017, la cifra alcanzó los 4,860 (357 del fuero federal y 4,503 del fuero común).

En suma, en el último lustro, Guanajuato ha mostrado una tendencia hacia la alza; teniendo su cifra más alta en junio de 2018.

\section{iii. Durango}

En 2013, Durango tenía una cifra absoluta de 3128 privados de la libertad (135 del fuero federal y 2993 del fuero común); mientras que, para junio de 2018, la cifra subió a 3956 presos ( 87 del fuero federal y 3869 del fuero común). En cifras absolutas, en el último lustro, dicha entidad federativa elevó su cifra de privados de la libertad en 828 .

Entre esos años, la cifra de privados de la libertad ha tenido sus altibajos. En 2014, la cifra se elevó a 3438 (187 del fuero federal y 3251 del fuero común); mientras que, en 2015, la cifra ascendió aún más: había 3767 (148 del fuero federal y 3619 del fuero común). En 2016, la cifra bajó a 2975 (117 del fuero 
federal y 2,858 del fuero común); para repuntar, al año siguiente, a 3449 (98 del fuero federal y 3351 del fuero común).

En suma, en el último lustro, Durango se encuentra con una tendencia de altibajos; su cifra más baja la tuvo en 2016.

\section{iv. Chihuahua}

En 2013, Chihuahua tenía una cifra absoluta de 7547 privados de la libertad (803 del fuero federal y 6744 del fuero común); mientras que, para junio de 2018, la cifra se disparó a 8241 (789 del fuero federal y 7452 del fuero común). Con respecto al total de presos, en el último lustro, Chihuahua elevó su población penitenciaria en 694.

En 2014, la cifra de personas privadas de su libertad ascendió a 7912 (876 del fuero federal y 7036 del fuero común); mientras que, en 2015, la cifra rondó los 8287 (970 del fuero federal y 7317 del fuero común). En 2016, la cifra de bajó con respecto al año anterior -8016 (901 del fuero federal y 7115 del fuero común)-; aunque volvió a subir en 2017: en ese año, la cifra fue de 8079 (708 del fuero federal y 7371 del fuero común).

A diferencia de la mayor parte de las entidades federativas, Chihuahua muestra una tendencia hacia la alza; su cifra más alta fue en 2015.

\section{v. Zacatecas}

En 2013, Zacatecas tenía una población penitenciaria de 1,263 privados de la libertad (288 del fuero federal y 975 del fuero común); mientras que, en junio de 2018, la cifra absoluta de presos era de 1815 (537 del fuero federal y 1278 del fuero común). Así, se puede ver que, en el último lustro, Zacatecas tuvo un mayor número de personas privadas de su libertad: 552 (249 del fuero federal y 303 del fuero común)

Entre esos años, las cifras sobre población penitenciaria tuvieron una tendencia a la alza. En 2014, el número de personas privadas de libertad era de 1474 (418 del fuero federal y 1056 del fuero común); en 2015, la cifra ascendió a 1570 (433 del fuero federal y 1137 del fuero común); en 2016, la cantidad de personas privadas de su libertad bajó a 1538 (456 del fuero federal y 1082 del fuero común); y, en 2017, la cifra volvió a subir: se ubicó en 1733 (521 del fuero federal y 1212 del fuero común). 
En síntesis, se puede decir que, en el último lustro, Zacatecas ha sido de las pocas entidades federativas que ha tenido un ascenso en su población penitenciaria; junio de 2018 fue su período con mayor cantidad de privados de la libertad.

\section{b) Incremente considerable}

No se registraron coincidencias con respecto a esta categoría; el incremento de la prisión preventiva fue entre 301 y 500 .

\section{c) Incremento leve ${ }^{7}$}

\section{i. Hidalgo}

En 2013, Hidalgo tenía una población penitenciaria de 3659 privados de la libertad (277 del fuero federal y 3382 del fuero común); mientras que, en junio de 2018, su cifra de presos era de 3955 (225 del fuero federal y 3730 del fuero común). En cifras absolutas, la cantidad de presos -en el último lustro- ha tenido un ascenso de 296.

Entre esos años, la cifra ha tenido una serie de altibajos. En 2014, la cantidad de privados de la libertad era de 4135 (319 del fuero federal y 3816 del fuero común). Sin embargo, a partir de ese año, la tendencia vino a la baja: en 2015, la población penitenciaria era de 4131 (261 del fuero federal y 3870 del fuero común); en 2016, la cifra era de 3784 (223 del fuero federal y 3561 del fuero común); y, en 2017, la cantidad de presos descendió a 3822 (219 del fuero federal y 3603 del fuero común).

En términos generales, Hidalgo muestra una tendencia de altibajos; tuvo su cifra más baja en 2017.

Para terminar con el presente apartado, es necesario hacer la apreciación con base en lo anteriormente expuesto y lo podemos constatar si apelamos a las cifras que nos provee el Órgano Administrativo Desconcentrado de Prevención y Readaptación Social (OADRPS). Según este ente, la cifra de presos que se encuentra en calidad de procesados es menor desde la publicación de la reforma constitucional. En 2008, el total de procesados era de 88935 (19 373 del fuero federal y 69562 del fuero común); mientras que, para junio de 2018, la cantidad de procesados bajó a 79195 (16 155 del fuero federal y 63040 del fuero común).

La misma aseveración se puede realizar en torno al Código Nacional de Procedimientos Penales, cabe recalcar, que las primeras entidades federativas en donde

7 Se incrementó en 50 y 300 el número de personas a las que se les impuso prisión preventiva durante 2013 y 2018. 
operó ese ordenamiento jurídico fueron Puebla y Durango, en Septiembre de 2014.

Para el año 2014, el total de procesados era de 107295 (24, 831 del fuero federal y 82464 del fuero común); 28100 presos más (8 676 del fuero federal y 19424 del fuero común) que en junio de 2018. En ese orden de ideas, se puede argüir que, tanto la reforma constitucional como la aprobación del Código Nacional de Procedimientos Penales, han servido para lograr el principal objetivo que se tiene en materia penitenciaria: bajar el índice de personas privadas de su libertad en calidad de procesadas.

\section{A modo de reflexión}

La problemática de los centros penitenciarios todavía está vigente y parte, en primer lugar, de la resistencia a reducir el uso de la prisión preventiva. Es evidente que, hasta que no se refuerce el papel de las unidades para evaluar el riesgo procesal en todo el país, se acudirá a la prisión como medida para evitar la libertad condicional cuando sea factible.

Aunque los cambios normativos de la reforma de 2011 iban encaminados a imponer la prisión de manera excepcional, en 2019, el incremento de delitos, en los lugares donde lamentablemente se impone prisión preventiva de manera oficiosa, se convirtió en un revés al espíritu del modelo de justicia penal cuyo eje central es la presunción de inocencia.

Sin embargo, la población carcelaria se redujo en gran medida y del análisis de las cifras se extrajo que el número de prisiones se redujo en la mayor parte de las entidades federativas, en 20 en un total de 32. Destaca la Ciudad de México con la cifra de reducción de un total de 13630 personas con prisión preventiva, seguido por Baja California y Sonora que rondan a las 5000 personas en dicha situación.

Por su parte, desafortunadamente se detectó un incremento alto en cinco entidades, lo cual se convierte en una cuestión bastante preocupante. El incremento se dio en el Estado de México, Guanajuato, Durango, Chihuahua y Zacatecas y que superó las 500 personas; destaca en gran medida el Estado de México ya que la cifra de incremento en el número de personas es de 8407 personas. Destaca también el Estado de Michoacán donde el número prácticamente es el mismo, apenas 14 personas de diferencia entre 2013 y 2018. 
Se valora de manera positiva la reducción de manera general en gran parte del país. En cuanto al incremento elevado en las cinco entidades federativas sería necesario analizar detenidamente la situación que vive cada uno de estos, pero eso supera el objetivo del presente estudio.

Por último, es necesario advertir que, ante los cambios normativos presentados en el art. 19 constitucional en 2019, se prevé que la tendencia al uso de prisión preventiva sea, desafortunadamente, al alza. Vamos a esperar a ver cómo se desarrolla el reforzamiento de las instituciones para operar el sistema penal acusatorio y si finalmente se dará un mejor desempeño y apoyo a los servicios cautelares con el fin de no acudir a la penosa prisión preventiva oficiosa. Debemos continuar en otra dirección, en la que se humanice a la sociedad, y atender esta problemática sin acudir al aislamiento que a lo único que contribuye es a alimentar la gran desfragmentación social que vive el país.

\section{Referencias}

Abella Fernández, C., Hernández Catalán, G y Barca Soler, M. (2009). Manual práctico de derecho penitenciario. Madrid: Tirant lo Blanch

Aguilar Cuevas, M. (2006). Las tres generaciones de derechos humanos. Revista de Derechos Humanos, (30). 93-99

Arenal, C. (2010). Estudios penitenciarios. España: Editorial Alicante

Armenta, F. (2011). Procedimientos penitenciarios, España: Editorial Comares.

Baratta, A. (2004). Principios Del Derecho Penal Mínimo (Para Una Teoría De Los Derechos Humanos Como Objeto Y Limite De La Ley Penal, en Criminología y Sistema Penal (Compilación in memoriam). Argentina: Editorial B de F.

Cámara de Diputados. (2019). Informe de la Cámara de Diputados, Boletín 1087 de Comunicación Social. Recuperado de: http://www5.diputados.gob.mx/index.php/ esl/Comunicacion/Boletines/2019/Febrero/19/1087-Aprueba-Camara-de-Diputados-con-mayoria-calificada-reforma-constitucional-en-materia-de-prision-preventiva-oficiosa

Cappelletti, M y Garth, B. (1984). El Acceso a la Justicia, Argentina: Colegio de Abogados del Departamento Judicial de la Plata.

Carrancá Rivas, R. (1981). Derecho penitenciario. Cárcel y penas. México: Editorial Porrúa. 
Cervelló Donderis, V. (2016). Derecho penitenciario. Valencia: Tirant lo Blanch.

Consejo de la Judicatura Federal. (2011). Presunción de Inocencia, El nuevo sistema de justicia penal acusatorio, desde la perspectiva constitucional. México: Poder Judicial de la Federación.

Cossío, J., Mejía R y Rojas L. (2015). La construcción de las restricciones constitucionales a los derechos humanos, "Estudio y documentos a partir de las contradicciones tesis 293/2011 y 21/2011”. México: Editorial Porrúa.

Ferrajoli, L. (2010). Democracia y Garantismo. Madrid: Editorial Trotta.

Fix-Zamudio, H. (2001). Los derechos humanos y su protección jurídica y procesal en Latinoamérica [Conferencia Magistral]. México: UNAM.

García Aguilar D. (2015). Presunción de Inocencia. México: Colección de textos sobre Derechos Humanos.

García Ramírez, S y Morales Sánchez, J. (2015). La Reforma Constitucional sobre Derechos Humanos 2009-2011. México: Editorial Porrúa.

Gobierno de México. (2016). Ley del Sistema Nacional de Anticorrupción. Recuperado de: https:/www.gob.mx/sfp/acciones-y-programas/ sistema-nacional-anticorrupcion-64289

Gómez Colomer, J. (2018). El sistema de enjuiciamiento criminal propio de un estado de derecho. Colección nuevo sistema. México: Inacipe

Le Clercq Ortega, J y Sánchez Lara, G. (2018). Índice global de impunidad igi-mex. Recuperado: https:/www.udlap.mx/igimex/assets/files/2018/igimex2018_ESP.pdf, p. 8 .

López Aguilar, M. (2015). Presunción de inocencia derecho humano en el sistema penal acusatorio. México: Instituto de la Judicatura Federal.

Mir Puig, C. (2012). Derecho penitenciario: el cumplimiento de la pena privativa de libertad. Barcelona: Atelier Libros Jurídicos.

Ortega Gutiérrez, D. (2003). Artículo 24 [Sinopsis]. Recuperado de: http://www.congreso.es/consti/constitucion/indice/sinopsis/sinopsis.jsp?art=24\&tipo=2

Pinto, R. Los motivos que justifican la prisión preventiva en la jurisprudencia extranjera Instituto Jurídicas de la UNAM, Recuperado de: https://revistas-colaboracion. juridicas.unam.mx/index.php/latinoamericana-derecho/article/view/21375/19048. 
Salazar Quiñonez, A. (2019). Los retos del proceso penal acusatorio ante la protección de los derechos humanos. México: Instituto Nacional de Ciencias Penales.

Sanz Mulas, N. (2017). Política criminal. Salamanca: Ratio Legis.

Serrano Cuellar González, N. (1990). Proporcionalidad y Derechos Fundamentales en el Proceso Penal. Madrid España: Editorial Constitución y Leyes (COLEX)

Túnnermann Bernheim, C. (1997). Los derechos humanos: evolución histórica y reto educativo. Caracas: UNESCO.

Vélez Mariconde, A. (2004). Derecho Procesal Penal Buenos Aires: Ediciones Lerner. 
